\title{
A multispecies system for evaluation of infectivity and pathogenicity of microbial pest control agents in nontarget aquatic species*
}

\author{
John W. Fournie, Steven S. Foss, John A. Couch \\ US Environmental Protection Agency, Environmental Research Laboratory, Sabine Island, Gulf Breeze, Florida 32561, USA
}

\begin{abstract}
Microbial pest control agents (MPCAs - viruses, bacteria, protozoa, fungi) are being used as biological pesticides and herbicides. Many of these agents are considered potential MPCAs and could be used widely in the environment. Therefore, test animals must be selected and laboratory systems developed to evaluate safety of such agents to nontarget species. A simple, multispecies laboratory system has been designed and used to determine risks of infectivity and pathogenicity of Colletotrichum gloeosporioides (Collego ${ }^{(i)}$ ), a registered postemergent mycoherbicide, to nontarget freshwater and estuarine plant and animal species. Test organisms included a freshwater and an estuarine fish, crustacean, bivalve mollusc, and plant. These multispecies systems also permit evaluation of other MPCAs against nontarget aquatic species and provide a standardized procedure for safety testing. Results from this study have shown these multispecies test systems to be viable, inexpensive, and reliable. Histopathological methods used indicated no evidence that experimental exposure to the fungal MPCA in our test system caused infection or related pathogenicity in the selected nontarget species.
\end{abstract}

\section{INTRODUCTION}

Biological control agents are of increasing importance in pest control concepts. Certain of these agents (e. g. viruses, bacteria, protozoa, fungi) have been produced and others, both natural and genetically altered, are being developed as insecticides and herbicides. Because these microbial pest control agents (MPCAs) could be widely disseminated in the environment, methods must be developed to evaluate their safety for nontarget species (Korp 1975, Environmental Protection Agency 1982). The US Environmental Protection Agency (USEPA) is responsible for providing guidelines to potential producers of MPCAs for methods to determine the safety of the agents to nontarget species in the USA.

Previous studies were concerned with single species tests designed to evaluate methods for exposing and

- Contribution No.640, Gulf Breeze Environmental Research Laboratory

- Mention of commercial products does not imply endorsement by the US Environmental Protection Agency determining effects of various MPCAs in nontarget, estuarine fish and crustaceans (Couch et al. 1984, Couch et al. 1985, Foss et al. 1986). The present study describes results of the design, development, and laboratory testing of a simple multispecies system for determining risks of infectivity and pathogenicity of a fungal mycoherbicide by waterborne exposure to 4 nontarget aquatic species. We used the fungal pest control agent Colletotrichum gloeosporioides f. sp. aeschynomene which is commercially available and marketed as Collego ${ }^{B} \cdot$ It is a registered, postemergent herbicide now being applied to rice and soybean fields to control the northern jointvetch weed (Aeschynomene virginica). Collego ${ }^{\circledR}$ is a 2 -component product: Component $\mathrm{A}$ is a water soluble isomerose fructose solution that serves as a spore rehydrating agent and Component $\mathrm{B}$ is a wettable powder formulation containing living fungal spores of $C$. gloeosporioides. After application, fungal spores penetrate the stem epidermis via appressoria and stem trichomes (TeBeest et al. 1978a). Intracellular mycelia then grow within the cortex, cambium, and xylem, resulting in an anthracnose type disease which produces lesions that completely encircle the stems of northern jointvetch plants 
The purpose of developing and evaluating the multispecies test system was to provide a method whereby functional assemblages of nontarget aquatic species could be exposed to MPCAs utilizing a standard procedure for testing. The methods used provide the potential to gain possible information on interaction, fate, and effects of an MPCA in a system more complex than single species test systems. We believe the methods reported here are adaptable for laboratory evaluations of the risks of many MPCAs to representative groups of nontarget, aquatic plants and animals.

\section{MATERIALS AND METHODS}

Test organisms. All organisms utullzed in our tests are listed in Table 1; they were collected with dip nets, pole seines, or by hand from local waters near the Gulf Breeze Environmental Research Laboratory, Florida, USA, or obtained from local commercial fishermen. A specialized technique, however, was employed in the collection of estuarine plants. Cores were taken from seagrass beds using a cylindrical coring device (Morton et al. 1986), brought to the surface, placed into portable plant boxes ( 4 cores per box), and transported to the laboratory test tanks.

Positive control bioassay. Viability and infectivity of the mycoherbicide Collego ${ }^{(1)}$ was determined by a positive control bioassay using the northern jointvetch weed Aeschynomene virginica. Plants were grown from seeds obtained from Dr Roy Smith, USDA, Agricultural Extension Service, Stuttgart, Arkansas (USA). Seeds were scarified, wrapped in a moist paper towel in a culture dish, and placed in an incubator for $48 \mathrm{~h}$ at $26^{\circ} \mathrm{C}$. After $48 \mathrm{~h}$, germinated seeds were planted in styrofoam cups containing potting soil and placed under special lighting conditions used in our MPCA aquaria test systems (see description of lighting for estuarine test system). A photoperiod of $16 \mathrm{~h}$ light$8 \mathrm{~h}$ dark and a temperature of $26^{\circ} \mathrm{C}$ (with lights on) were maintained until the plants attained 15 to $20 \mathrm{~cm}$ in height. Ten plants were randomly selected for exposure to Colletotrichum gloeosporioides, the active fungal agent in Collego ${ }^{\circledR}$. Another 10 plants were designated as nonexposed controls. Plants were exposed to a suspension of Collego ${ }^{3}$ containing 2 million spores per $\mathrm{ml}$ by misting with an atomizer until the surface of the plants was thoroughly wet (TeBeest et al. 1978b). Plants were then placed in a dew chamber consisting of a $75 \mathrm{l}$ aquarium containing an open-top, $1 \mathrm{l}$ bottle of water kept at a constant $30^{\circ} \mathrm{C}$. When covered and darkened, the temperature in the chamber remained at $27^{\circ} \mathrm{C}$, with a high relative humidity. After $24 \mathrm{~h}$ the curtain was removed and exposed plants remained in the chamber under the above photoperiod. All control and exposed plants were examined daily for evidence of disease development. Samples of infected and control stem tissues were processed for histological examination.

Preliminary tests. Preliminary studies were conducted primarily to determine if the test animals could survive in the designed system for $28 \mathrm{~d}$ and if good water quality could be maintained. Additional reasons for conducting these tests were to (1) determine if there was an acute toxic response to the rehydrating agent and/or rehydrating agent plus spore mixture, (2) establish a concentration range for chronic exposures, (3) determine if our multispecies test system could accommodate this type of MPCA.

The preliminary multispecies test system consisted of two $64 \mathrm{l}$ aquaria with $15 \mathrm{~cm}$ high plexiglass inserts (Fig. 1) which held the turtle grass cores in place. Absence of an undergravel filter provided the necessary anaerobic sediment for the seagrass. A biological sponge filter was placed in the center of each tank. Ten American oysters were placed on the tank bottom, 15 grass shrimp were maintained in individual cups (Fig. 1) to prevent cannibalism, and 15 sheepshead minnows were released into the water column. Water temperature was maintained at $26^{\circ} \mathrm{C}$, and the salinity of the seawater was approximately $26 \%$.

For the preliminary study, one tank received rehy-

Table 1. Multispecies test organisms

\begin{tabular}{|lll|}
\hline Phyletic group & \multicolumn{1}{c}{ Estuarine } & Freshwater \\
\hline Fish & Sheepshead minnow & Mosquitofish \\
& Cyprinodon variegatus & Gambusia affinis \\
Crustacean & Grass shrimp & Grass shrimp \\
& Palaemonetes pugio & Palaemonetes kadiakensis \\
Bivalve mollusc & American oyster & Asian clam \\
& Crassostrea virginica & Corbicula manilensis \\
Plant & Turtle grass & Anacharis \\
& Thalassia testudinum & Egeria densa \\
\hline
\end{tabular}


Fig. 1. Preliminary multispecies test system

drating agent only (2.5 g rehydrating agent $\mathrm{l}^{-1}$ ), the second tank received the rehydrating agent-spore mixture containing appromiximately 2 million spores $\mathrm{ml}^{-1}$. Animals were observed daily for behavioral changes, gross signs of infection, and mortality. At the end of the test, representative animals were examined histologically to evaluate possible effects associated with exposures. Temperature, $\mathrm{pH}$, and dissolved oxygen were measured periodically throughout the test.

Because of the oyster mortalities in the preliminary test, an additional test exposing only oysters to rehydrating agent was performed to determine their sensitivity to this component. Twenty oysters were placed into each of three 37 l aquaria equipped with a biological (sponge) filter containing seawater with a salinity of $22 \%$. Water temperature was maintained at ca $25^{\circ} \mathrm{C}$. Concentration of rehydrating agent used in test Tank 1 was $2.5 \mathrm{~g} \mathrm{l}^{-1}$ (same as preliminary multispecies test) and the concentration in test Tank 2 was $1.25 \mathrm{~g} \mathrm{l}^{-1}$. No rehydrating agent was added to the control tank. Oysters were carefully monitored daily and moribund animals were removed for histologic examination. Scheduled histologic samples were taken on Days 3, 5, 6 , and 7 post exposure and temperature, $\mathrm{pH}$, and dissolved oxygen were monitored daily during the test period.

Estuarine multispecies test. Organisms utilized in the estuarine tests (Table 1) were acclimated to laboratory conditions for 10 to $14 \mathrm{~d}$, and their overall condition was carefully monitored.

Three 112 l glass aquaria were used for this system (Fig. 2A). Turtle grass cores were contained in a portable plexiglass plant box $(17.5 \times 30 \times 30 \mathrm{~cm})$ at one end of each aquarium. The remaining tank bottom was covered with crushed coral over an undergravel filter
(Fig. 2A). Fifteen oysters were placed in each aquarium and the tanks were maintained on flow-through seawater for $24 \mathrm{~h}$. When oysters were open and feeding, the remaining test animals (20 sheepshead minnows and 15 estuarine grass shrimp held in individual holding cups) were added and the flow-through seawater was discontinued. The now static systems were covered, and a constant temperature of $27^{\circ} \mathrm{C}$ was maintained using a submersible aquarium heater

To determine the best lighting conditions for maintaining turtle grass in the laboratory, a LI-COR LI$188 \mathrm{~B}^{\mathrm{B}}$ photometer was used to quantify the light energy received by plants at the collection site. The light energy reaching the bottom at $2 \mathrm{~m}$ was $340 \mu \mathrm{E} \mathrm{m} \mathrm{m}^{-2}$ $\mathrm{s}^{-1}$. To duplicate this light energy as closely as possible in the laboratory, four $400 \mathrm{~W}$ multivapor halide lamps in metal street light housings were installed $53 \mathrm{~cm}$ above the water surface. Light energy on the aquarium bottoms measured approximately $260 \mu \mathrm{E} \mathrm{m} \mathrm{m}^{-2} \mathrm{~s}^{-1}$. Photoperiod consisted of $16 \mathrm{~h}$ light and $8 \mathrm{~h}$ dark.

Exposure of test organisms was accomplished by an initial application of Collego directly into the water column $\left(6.24 \times 10^{4}\right.$ spores $\left.\mathrm{ml}^{-1}\right)$ followed by a second application $14 \mathrm{~d}$ later. The second tank received $78 \mu \mathrm{ll}^{-1}$ rehydrating agent only. A third tank served as a control. Fish and shrimp were fed a commercially available flake food. To detect any significant changes in water quality during the test, salinity, $\mathrm{pH}$, and dissolved oxygen were monitored periodically.

Freshwater multispecies test. Organisms utilized in this test (Table 1) were also acclimated to laboratory conditions for 10 to $14 \mathrm{~d}$ prior to placement in test aquaria. Animals were monitored carefully during this period. 


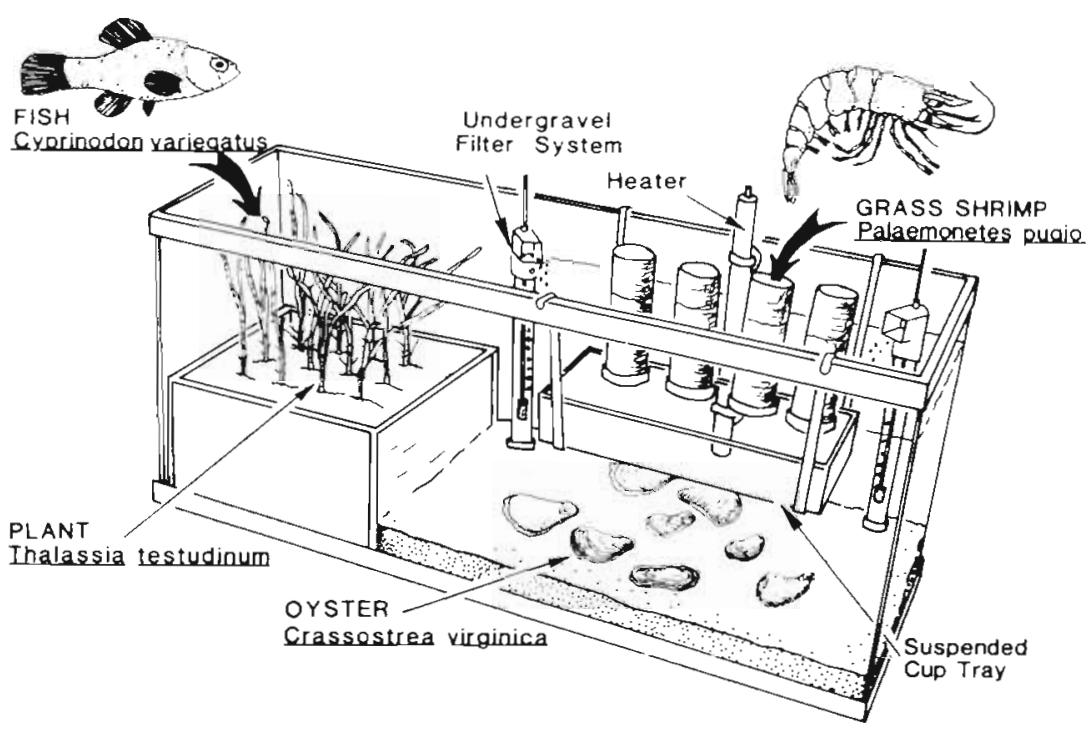

A

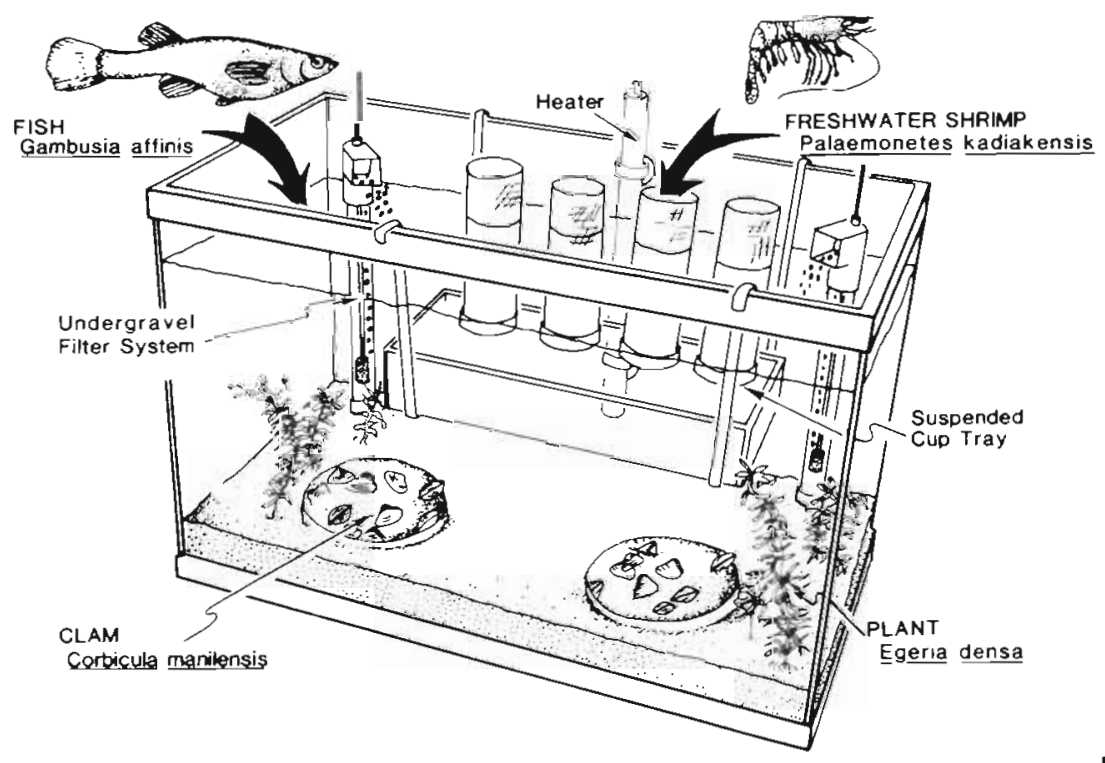

Fig. 2. Recirculating static test systems.

(A) Estuarine multispecies test system;

(B) freshwater multispecies test system

B

Three 76 l glass aquaria were utilized for this test. Tank bottoms were covered with undergravel filters over which a $3 \mathrm{~cm}$ layer of natural gravel was placed (Fig. 2B). Twenty mosquito fish and 10 freshwater grass shrimp, placed into individual holding cups, were added to each tank. Twenty freshwater clams (2.0 to $2.5 \mathrm{~cm}$ ) were equally divided between 2 containers constructed of round plastic rings ca $9.5 \mathrm{~cm}$ in diameter and $2 \mathrm{~cm}$ in height with a screen bottom. Containers were placed into the gravel substrate but could be easily removed for inspection of clams. Lastly, 15 plants were rooted into the gravel substrate.

Exposure of test organisms was accomplished as described for the estuarine system and the 3 tanks were treated identically. To detect any significant changes in water quality during the test period, temperature, $\mathrm{pH}$ and dissolved oxygen were monitored periodically.

Histologic procedures. Fish, shrimp, and molluscs from the freshwater tests were fixed in $10 \%$ neutral buffered formalin whereas the analogous organisms from the estuarine tests were fixed in Davidson's solution (Shaw \& Battle 1957). Plant tissue from both tests was fixed in FAA (Sass 1958), a fixative mixture containing formalin, ethyl alcohol, and acetic acid. Prior to processing, fish were decalcified in Decalcifier $\mathrm{B}^{\mathbb{B}}$, and shrimp were placed in a decalcifying solution consisting of 1 part formic acid, 1 part $95 \%$ ethyl alcohol, and 1 part $10 \%$ sodium acetate in $1 \%$ trichloro-acetic acid. Tissues were dehydrated in a series of Technicon Dehydrant S-29 ${ }^{\circledR}$, embedded in paraffin, and sections 
of animal tissues were cut at $6 \mu \mathrm{m}$ and plant tissues at 8 to $10 \mu \mathrm{m}$. Sections were stained with Harris' hematoxylin and eosin (Luna 1968).

\section{RESULTS}

\section{Positive control bioassay}

Positive controls were performed to determine if the spores were viable and to aid in the recognition of lesions in nontarget plant species.

Exposure of Aeschynomene virginica seedlings to a suspension of Colletotrichum gloeosporioides (Collego $\left.{ }^{(}\right)$containing ca 2 million spores $\mathrm{ml}^{-1}$ produced $100 \%$ infection and mortality within $5 \mathrm{~d}$. Formation of pinpoint lesions occurred on stems within 2 to $3 \mathrm{~d}$ after exposure. Infection resulted in the formation of prominent brownish-colored lesions that encircled the stem, causing tissue collapse by $5 \mathrm{~d}$ post exposure (Fig. 3). Upon close inspection, numerous appressoria were present in the area of the stem lesions.

Exposed plants exhibited all the histological features characteristic of a viable infection with Colletotrichum gloeosporioides (TeBeest et al. 1978a). The cytoplasm of infected cells was disrupted and hyphae (Fig. 4) were present within cortical, cambial, and pith ray tissues. Plant tissues beneath the surface of the lesions were collapsed and mycelial colonization was extensive within plant tissues. Hyphae were apparently sporogenous, producing the characteristic acervuli (Fig. 5). Death of Aeschynomene virginica seedlings was caused by collapse of infected stem tissues.

\section{Preliminary test}

In the multispecies test, only the oysters exhibited an acute toxic response as evidenced by mortalities in both tanks and histologic evaluation discussed below. Except for the individuals sampled prior to Day 6 post exposure, all oysters were dead within $4 \mathrm{~d}$ in the tank that contained rehydrating agent plus spores; all oysters died in the tank containing only rehydrating agent within $6 \mathrm{~d}$. Additionally, all 15 grass shrimp died within $5 \mathrm{~d}$ in the tank that contained rehydrating agent plus spores; however, these mortalities were probably due to the deterioration of the system. The $\mathrm{pH}$ dropped from 7.6 to 5.8 in $5 \mathrm{~d}$ and the DO dropped from 6.9 to $0.8 \mathrm{mg} \mathrm{l}^{-1}$ in $24 \mathrm{~h}$. These severe changes in $\mathrm{pH}$ and DO did not occur in the tank with rehydrating agent only.

The only significant histologic changes in test animals occurred in oysters. Normal appearing vesicular connective tissue, digestive diverticula, and patent blood sinuses were noted in histologic sections from the 19 surviving control oysters (Fig. 6). Oysters exposed to rehydrating agent exhibited atrophy of digestive diverticula, blood sinuses packed with hemocytes, and numerous foci of hemocytes within the vesicular connective tissue (Fig. 7).

In oyster exposures to rehydrating agent only, the water in both experimental tanks clouded by $24 \mathrm{~h}$ post exposure and remained so throughout the $8 \mathrm{~d}$ exposure period. By Day 7 post exposure, 2 oysters in the lower concentration and 5 oysters in the higher concentration had died.

At both the lower and higher concentrations, $44 \%$ and $53 \%$ of the oysters, respectively, exhibited some of the histopathological changes observed in oysters from the preliminary multispecies test. These changes were most pronounced from Days 3 to 7 post exposure. The histopathological changes included a significant hemocytic infiltration of vesicular connective tissue, atypical hemocytic occlusion of blood sinuses, and epithelial atrophy of non-ciliated digestive gland diverticula (Fig. 8).

\section{Estuarine multispecies test}

Mortality was low among plants and animals during the $28 \mathrm{~d}$ test period. Only 3 oysters died in the control tank during the test. In the experimental tanks, no fish died, only 2 of 45 shrimp died, and 6 of 45 oysters died. Otherwise, test animals exhibited no behavioral changes or signs of stress after addition of the rehydrating agent or rehydrating agent plus spore mixture. The physical and chemical parameters were maintained at a relatively constant level throughout the test period. Water temperature was maintained at $27^{\circ} \mathrm{C}$, salinity at $21 \%$, dissolved oxygen at $8.3 \mathrm{mg} \mathrm{l}^{-1}$, and the average $\mathrm{pH}$ was 7.8 .

Histological examination of fish visceral masses, grass shrimp, oysters, and plants showed no signs of infection by the fungus; no other pathological changes were noted in examined tissues.

\section{Freshwater multispecies test}

No mortality occurred among the plants and animals during the $28 \mathrm{~d}$ test period in either control or experimental aquaria. Additionally, none of the test animals exhibited any signs of stress or changes in activity or feeding behavior after addition of rehydrating agent or rehydrating agent and spore mixture. The physical parameters were maintained at a fairly constant level throughout the test period. Water temperature was maintained at $26^{\circ} \mathrm{C}$, the average pH was 7.5 in all 3 

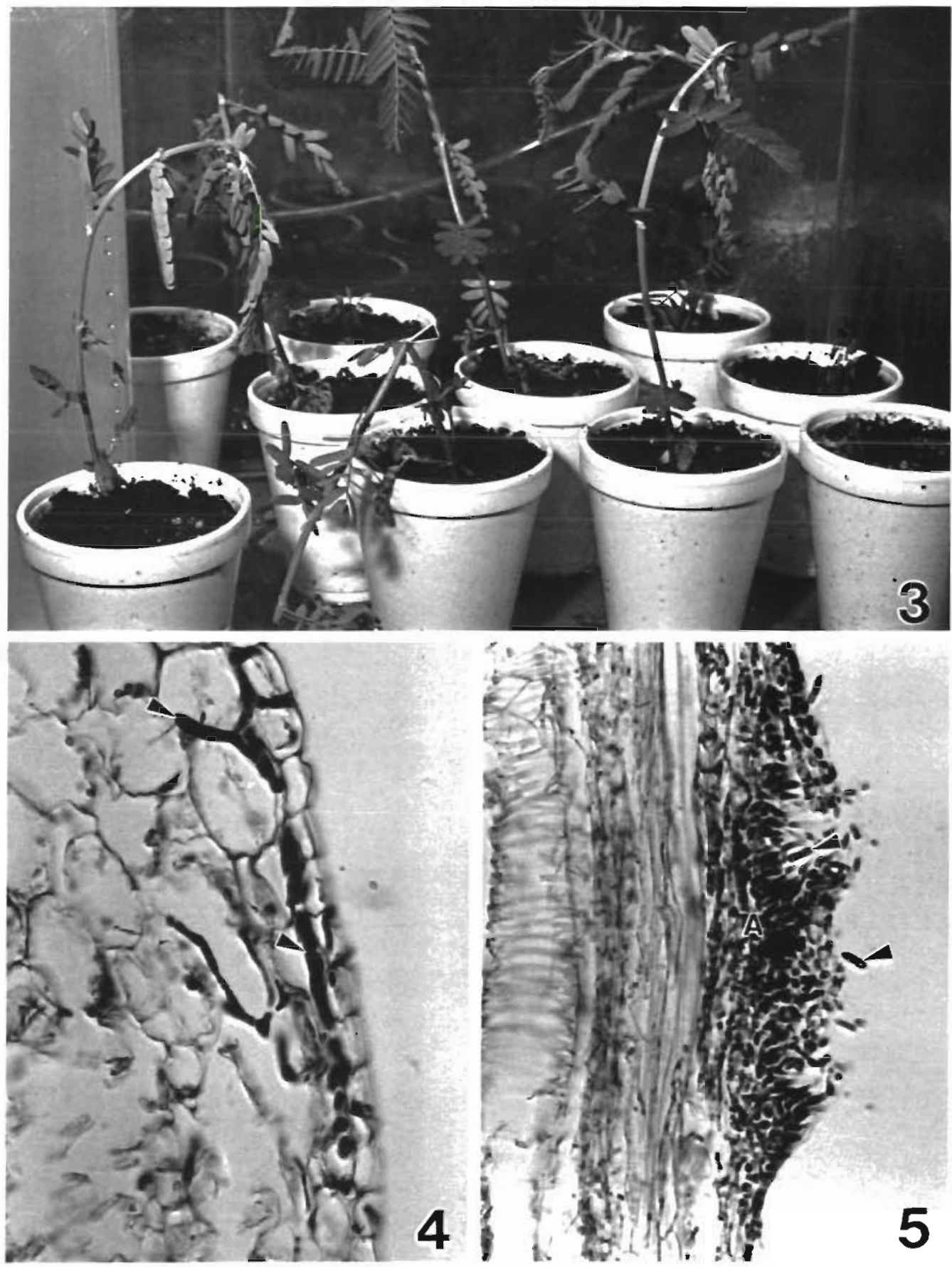

Figs. 3 to 5. Aeschynomene virginica. Fig. 3. Northern jointvetch plants infected with Colletotrichum gloeosporioides; note collapsed stem (arrowhea a). Fig. 4. Cross section through infected plant showing sporogenous hyphae (arrowheads) in epidermis and cortex; $\mathrm{H} \& \mathrm{E}, \times 500$. Fig. 5. Longitudinal section of infected plant through acervulus $(A) ;$ note spores (arrowheads); $\mathrm{H} \&$ $E_{1} \times 250$

aquaria, and the dissolved oxygen remained at approximately $8.5 \mathrm{mg}^{-1}$

Histological examination of fish visceral masses, grass shrimp, clams, and plants showed no signs of infection by the fungus; no other pathologicial changes were noted in any of the examined tissues

\section{DISCUSSION}

It has been demonstrated (Couch et al. 1986) that 3 to 4 different nontarget species can be successfully maintained in a closed system for a $30 \mathrm{~d}$ period. Their species included representatives from 3 estuarine phy- 


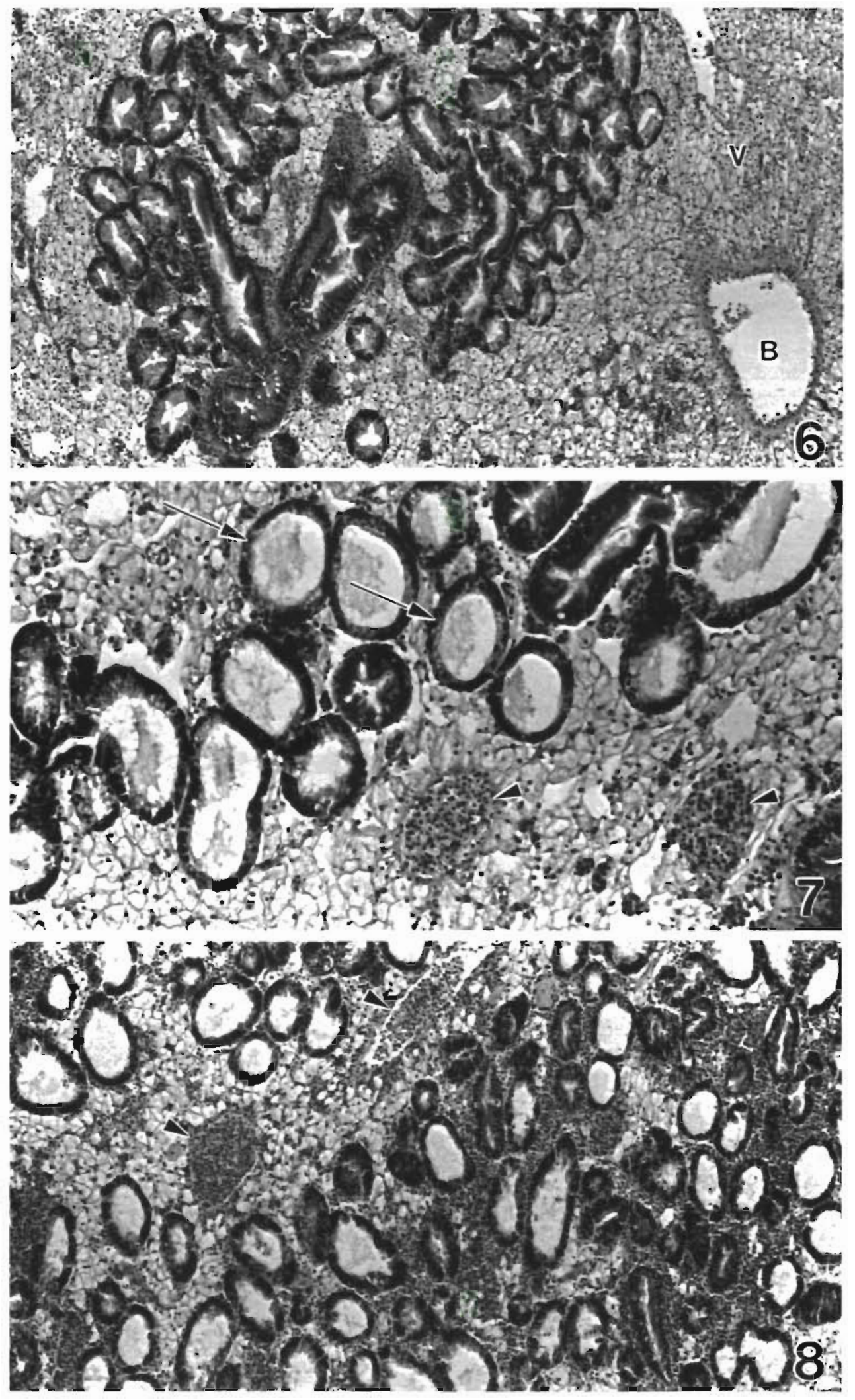

Figs. 6 to 8. Crassostrea virginica. Histologic sections through oysters; H \& E. Fig. 6. Control oyster showing numerous digestive tubules, lacy vesicular connective tissue $(V)$, and a patent blood sinus $(B) ; \times 125$. Fig. 7 . Oyster exposed to $2.5 \mathrm{~g} \mathrm{l}^{-1}$ rehydrating agent; note atrophy of digestive tubule epithelia (arrows) and blood sinuses packed with hemocytes (arrowheads); $\times 250$. Fig. 8 . Oyster exposed to $1.25 \mathrm{~g} \mathrm{l}^{-1}$ rehydrating agent showing hemocytic infiltrate in vesicular connective tissue, blood sinuses congested with hemocytes (arrowheads), and atrophy of some digestive tubule ephithelia; $\times 125$ 
letic groups: 1 fish, Cyprinodon variegatus; 1 grass shrimp, Palaemonetes pugio; and 2 bivalve molluscs, Rangia cuneata and Crassostrea virginica. However, no plants were included and no MPCAs were tested in their system. We have designed a simple, inexpensive experimental system in which MPCAs can be evaluated for safety considerations in a group of nontarget aquatic species.

Our freshwater and estuarine multispecies test systems can accommodate at least 4 groups of nontarget aquatic hosts, both plant and animal, for a $28 \mathrm{~d}$ test period with minimal mortality and provide the necessary conditions for maintenance and growth of nontarget hosts during the exposure period. These conditions included maintaining various physical and chemical parameters within acceptable limits (e.g. temperature, $\mathrm{pH}$, dissolved oxygen) as well as providing specific requirements for certain organisms (e. g. plant boxes to provide anaerobic sediment for turtle grass).

The positive control bioassay of the fungus with northern jointvetch weed provided a relatively quick and easy laboratory control system to validate viability and infectivity of Colletotrichum gloeosporioides spores used in the nontarget aquatic species tests. No macroscopic or microscopic evidence of infectivity, pathogenicity, or toxicity was encountered in the examination of the aquatic plants and animals exposed to C. gloeosporioides even at a concentration 1000 times the field application rate. This was expected because studies designed to determine safety of MPCAs to nontarget hosts are usually based on the null hypothesis that infection and related effects to nontarget hosts will not occur.

The only significant mortalities and unusual histologic findings occurred in oysters from our preliminary multispecies test and oyster exposure. The observed histopathology was non-specific and was not a response to the test agent directly. Increased hemocytic response and atrophy of non-ciliated digestive tubule epithelium may have been due to an increased bacterial level in test aquaria which occurred because of the fructose-based rehydrating agent. Conditions in test aquaria (low nitrogen and high carbohydrate concentrations) were favorable for an initial increase in bacterial flora and their subsequent utilization of excess carbohydrate to produce complex polysaccharides and mucilages. All of these factors added to deterioration of these test systems. These problems were alleviated in our actual freshwater and estuarine multispecies tests because of design changes incorporated into the systems (e. g. increased tank volume, undergravel filtration) and decreased concentration of Collego

This simple, economical system could be utilized with all types of naturally occurring MPCAs, including viruses, bacteria, protozoans, and fungi. With incorporation of proper containment facilities, genetically altered MPCAs could also be tested in this system, with the addition of endpoints relevant to genetic monitoring. Furthermore, depending on the specific nature of the test agent, additional endpoints (i. e. serological testing. electron microscopy) for infectivity, pathogenicity, or toxicity could be utilized with this type of system. Finally, to broaden or narrow the focus of a specific test, other nontarget aquatic species could also be utilized in this system, providing their maximum size and physiologic requirements permitted their maintenance.

\section{LITERATURE CITED}

Couch, J. A., Duke, T. W., Foss, S. S., Perez. K. T. (1986) Enclosed systems for testing microbial pest control agents Proc. Workshop at ERL/Gulf Breeze sponsored by U.S. EPA, Office of Pesticides Programs, Washington, D. C.

Couch, J. A., Foss, S. S., Courtney, L. A. (1985). Evaluation for risks of an insect virus, bacterium, and protozoon to a nontarget, estuarine crustacean. Report EPA/600/X-85/ 290, U. S. EPA, Gulf Breeze, Florida

Couch, J. A., Martin, S. M., Tompkins, G., Kinney, J. (1984). A simple system for the preliminary evaluation of infectivity and pathogenesis of insect virus in a nontarget estuarine shrimp. J. Invertebr. Pathol. 43: 351-357

Environmental Protection Agency (1982). Pesticide assessment guidelines, subdivision $M$, biorational pesticides. Office of Pesticides and Toxic Substances, Washington, D. C.

Foss, S. S., Courtney, L. A., Couch, J. A. (1986). Evaluation of a fungal agent (Lagenidium giganteum) under development as an MPCA for nontarget risks. Report EPA/600/X-86/229, U. S. EPA, Gulf Breeze, Florida

Korp, H. (1975). Introductory remarks. In: Summers, M. (ed.) Baculoviruses for insect pest control: safety considerations Am. Soc. Microbiol, Washington, D. C., p. 3

Luna, L. G. (1968). Manual of histologic staining methods of the Armed Forces Institute of Pathology, 3rd edn. McGraw Hill, New York

Morton, R. D., Duke, T W., Macauley, J. M., Clark, J. R., Price, W. A., Hendricks, S. J., Owsley-Montgomery, S. D., Plaia, G. R. (1986). Impact of drilling fluids on seagrasses: an experimental community approach, community toxicity testing. ASTM STP920. In: Cairns, J. Jr (ed.) American Society for Testing and Materials, Philadelphia

Shaw, B. L., Battle, H. I. (1957). The gross and microscopic anatomy of the digestive tract of the oyster Crassostrea virginica (Gmelin). Can. J. Zool, 35: 325-34.7

Sass, J. E (1958). Botanical microtechnique, 3rd edn. The Iowa State University Press, Ames, Iowa

TeBeest, D. O., Templeton, G. E., Smith, R. J., Jr (1978a). Histopathology of Colletotrichum gloeosporioides f. sp. aeschynomene on northern jointvetch. Phytopathology 68: $1271-1275$

TeBeest, D. O., Templeton, G. E., Smith, R. J., Jr (1978b). Temperature moisture requirements for development of arithracnose on northern jointvetch. Phytopathology 68: 389-393 